\title{
Effects of 4-Aminopyridine on the Non-adrenergic Inhibitory Neurotransmission in the Guinea-pig Duodenum
}

\author{
Hiromichi OHKawa \\ Department of Physiology, Yamaguchi University \\ School of Medicine, Ube, Yamaguchi, 755 Japan
}

\begin{abstract}
The effects of 4-aminopyridine (4-AP) on the non-adrenergic inhibitory potential (i.p.) in the longitudinal and circular smooth muscle cells of the guinea-pig duodenum were investigated using intracellular microelectrodes. The membrane potential of both smooth muscles was decreased by 4-AP and the amplitude of the evoked i.p.s was increased. In a low-calcium solution $(0.25 \mathrm{~mm})$, the amplitude of the i.p.s was reduced but the additional application of 4-AP increased the amplitude. In the 4-AP containing low-calcium solution, the i.p. was inhibited by verapamil and EGTA. The inhibitory effect of verapamil on the i.p. evoked in a low-calcium solution was less in the presence of 4-AP than that in its absence. In a high-calcium solution ( $5 \mathrm{~mm}$ ), the amplitude of the i.p. increased and the additional application of 4-AP enhanced the i.p. further. The amplitude of the i.p. elicited in highpotassium solutions was not changed by 4-AP. The i.p. was not potentiated by 2 -aminopyridine or 2,5-diaminopyridine. Tetraethylammonium ions enhanced the amplitude of the i.p. at low concentration but decreased it in high concentration. In a few longitudinal smooth muscle cells, the evoked excitatory potential (e.p.) was observed. Potentiation of the e.p. by 4-AP was completely blocked by atropine. From the results obtained, it is suggested that the release of the nonadrenergic inhibitory neurotransmitter is increased by 4-AP due to increase calcium influx in the nerve terminals. The release of the cholinergic excitatory neurotransmitter seems to be increased by 4-AP.
\end{abstract}

Key Words: non-adrenergic inhibitory neurotransmission, duodenal smooth muscle, 4-aminopyridine, tetraethylammonium ion.

It has been reported by many authors that the release of cholinergic neuromuscular transmitter was potentiated by 4-aminopyridine (4-AP) (LUNDH and THESLEFF, 1977; MolGó et al., 1977, 1979, 1980; ILLÉS and THESLEFF, 1978; LunDH,

Received for publication June 22, 1984

大川博通 
1978; Bostock et al., 1981; BurLeY and JACOBS, 1981; CORTHAY et al., 1982; THOMSEN and WiLSON, 1983), 3,4-diaminopyridine (3,4-DAP) (DURANT and MARShAll, 1980; Glover, 1980; Molgó et al., 1980, ThOMSEN and Wilson, 1983), and 4-methyl-2-aminopyridine (4M-2-AP) (KILOH et al., 1981). The release of adrenergic neurotransmitter was also increased by 4-AP (KIRPEKAR et al., 1977) and 4M-2-AP (GLOVER, 1980).

As the mechanisms on the potentiation of cholinergic neurotransmitter release, the following hypotheses are suggested, 1) the blocking action of voltagesensitive potassium channels and prolongation of the nerve action potential (Llinás et al., 1976; KIrPeKAR et al., 1977; Molgó et al., 1977; THOMSEN and WILSON, 1983) and 2) a direct action of the voltage-sensitive calcium channels in nerves (LundH and TheslefF, 1977; Illés and THESLEFF, 1978; LundH, 1978; Molgó et al., 1980; BurleY and JACOBS, 1981). The inhibition of cholinesterase in the neuromuscular transmission by 4M-2-AP was also suggested (KILOH et al., 1981). As well, in the sympathetic nerves, it is suggested that 4-AP primarily inactivates potassium current and prolongs the action potential in nerves (KIRPEKAR et al., 1977). It is proposed that intestinal smooth muscles possess non-adrenergic inhibitory nerves (see review of BURNSTOCK, 1972). The identify of non-adrenergic inhibitory neurotransmitter is still uncertain, but the release of non-adrenergic inhibitory neurotransmitter was influenced by external divalent cations (HOLMAN and WeINRICH, 1975; LANG, 1979; Bauer and Kuriyama, 1982a; OhKaWA, 1984). Since the manner of release of the non-adrenergic inhibitory neurotransmitter appears to be similar to that of the cholinergic neuromuscular transmitter in skeletal muscles (Holman and WeInRICH, 1975; OHKAwA, 1984), it is likely that the release of non-adrenergic inhibitory neurotransmitter will be affected by 4-AP.

In the present experiments, the effects of 4-AP on the liberation of nonadrenergic inhibitory neurotransmitter in the guinea-pig duodenum were investigated. In the following experiments, the non-adrenergic inhibitory potentials in the duodenal smooth muscle cells were recorded intracellularly and the amplitude of these potentials was used as an index of the liberation of non-adrenergic inhibitory neurotransmitter. The results obtained suggest that the release of nonadrenergic inhibitory neurotransmitter in the duodenal wall is increased by 4-AP.

\section{METHODS}

Guinea-pigs of either sex weighing 300-400 g were stunned, bled, and a short segment (less than $3 \mathrm{~cm}$ from the pylorus) of duodenum was removed. The duodenum was opened along the mesenteric border and a full-thickness strip ( $4 \mathrm{~mm} \times$ $2 \mathrm{~mm}$ ) cut parallel to longitudinal axis. The strips were mounted serosal surface uppermost in an organ bath with approximately equal lengths of tissues being placed between the stimulating electrodes. Electrical field stimulation was applied through a pair of silver-silver chloride wire electrodes that was set up on 
each side of the preparation. Inhibitory potentials were recorded in response to rectangular pulses (usually $0.6 \mathrm{msec}$ duration at constant strength) with intracellular micro-electrode placed less than $1 \mathrm{~mm}$ from one of the stimulating electrodes. The micro-electrodes were inserted from the serosal side. In some experiments, the inhibitory potentials were recorded from the circular smooth muscle cells of duodenal preparations. In these preparations, the longitudinal muscle layer of the preparation was removed carefully and the recording electrodes were inserted from the serosal side.

The modified Krebs solution contained (mM): $\mathrm{NaCl} 122, \mathrm{KCl} 4.7, \mathrm{NaHCO}_{3}$ 15.5, $\mathrm{KH}_{2} \mathrm{PO}_{4} 1.2, \mathrm{CaCl}_{2} 2.5, \mathrm{MgCl}_{2} 1.2$, and glucose 11.5. The drugs used were as follows: 2-aminopyridine (2-AP, Nakarai Chem.), 4-aminopyridine (4-AP, Tokyo Kasei), atropine sulfate, 2,5-aminopyridine (2,5-DAP, Aldrick Chem.), and verapamil hydrochloride (Eisai).

Values of the measured parameters of muscle membrane and inhibitory potentials were expressed as the mean \pm S.E. ( $n=$ number of penetrations of the micro-electrode or number of observed inhibitory potentials). Statistical significance was assessed using Student's $t$-test.

\section{RESULTS}

\section{Effects of 4-AP on the inhibitory potentials}

The membrane potential of the longitudinal smooth muscle cells of the guineapig duodenum was $-51.0 \pm 0.5 \mathrm{mV}(n=100)$. When a brief pulse was given to the preparation, a small hyperpolarization (inhibitory potential, i.p.) was evoked. This potential was not abolished by the treatment with phentolamine $\left(10^{-6} \mathrm{~g} / \mathrm{ml}\right)$, propranolol $\left(10^{-6} \mathrm{~g} / \mathrm{ml}\right)$, and guanethidine $\left(10^{-6} \mathrm{~g} / \mathrm{ml}\right)$, as reported previously (OHKAwA, 1983). In general, "spontaneous" and evoked excitatory potentials (e.p., small depolarization) were not observed in duodenal preparations except in some cells as shown later. The mean amplitude of the i.p.s elicited by signle stimuli was $10.2 \pm 0.1 \mathrm{mV}(n=280)$. Repeated stimulation evoked successive i.p.s. The amplitude of these i.p.s was gradually reduced during the stimulation. Examples of the i.p.s evoked by single and repeated stimulations in normal solution are shown in Fig. 1C.

Effects of 4-AP on the resting membrane potential and the i.p.s of the duodenal smooth muscles were examined. As shown in Fig. 1A, the membrane was depolarized by 4-AP. When the $10^{-4} \mathrm{~g} / \mathrm{ml} \mathrm{4-AP}$ was given, the membrane potential changed to $-43.5 \pm 0.8 \mathrm{mV}(n=39)$. The relative amplitude of the i.p.s elicited by single stimuli was significantly $(p<0.001)$ increased at concentration greater than $10^{-8} \mathrm{~g} / \mathrm{ml}$ 4-AP, as shown in Fig. 1B. The off-depolarization due to the preceeding i.p. was potentiated by 4-AP. In cells in which the i.p. could be evoked, an e.p. was not observed even in the absence of atropine and in the presence of 4-AP. In the presence of atropine $\left(10^{-6} \mathrm{~g} / \mathrm{ml}\right)$, the amplitude 
A

$$
\text { C }
$$
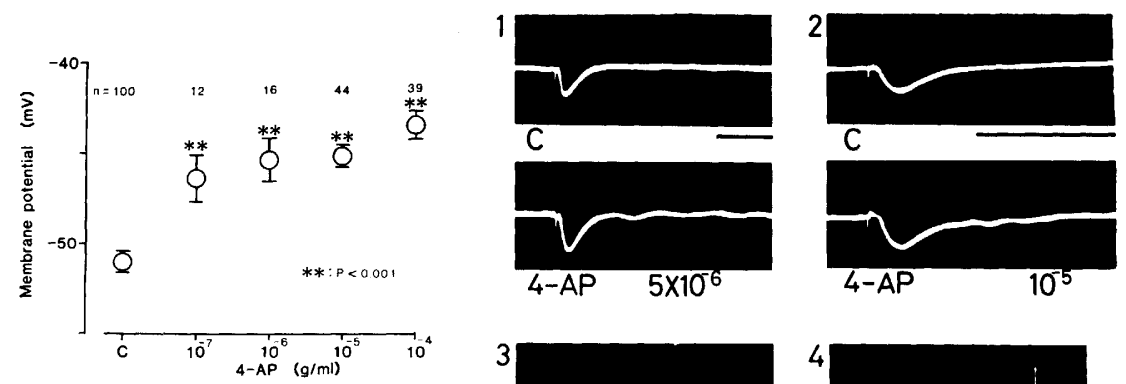

B
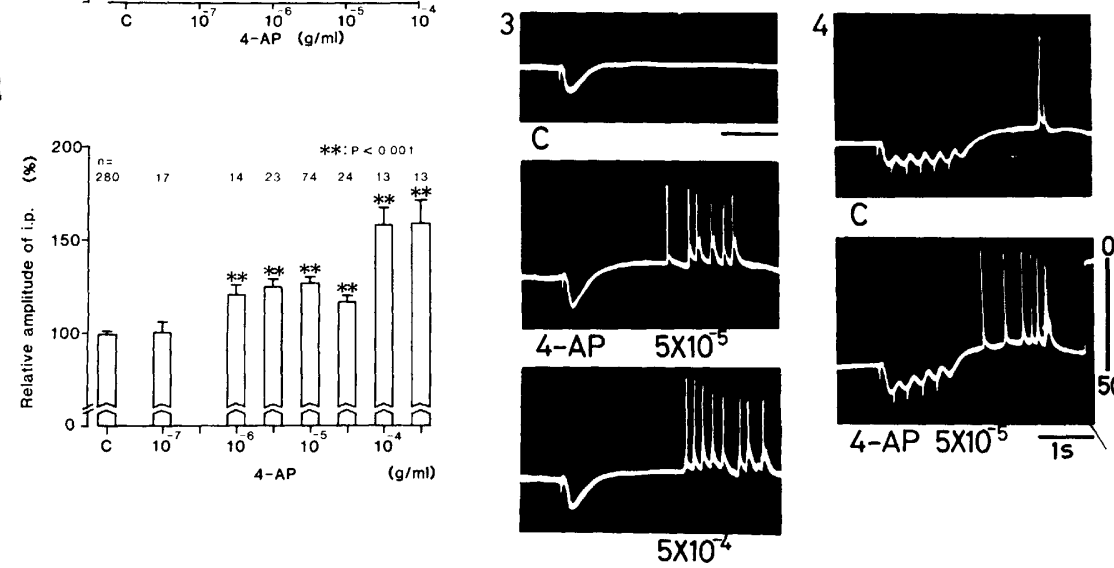

C

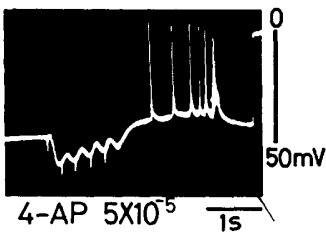

Fig. 1. Effects of 4-AP on the membrane potential and the amplitude of the i.p.s in the longitudinal smooth muscles of duodenum. (A) Membrane potential changes in 4-AP $\left(10^{-7}-10^{-4} \mathrm{~g} / \mathrm{ml}\right)$. (B) Changes in the relative amplitude of the i.p. by 4-AP $\left(10^{-7}-5 \times\right.$ $10^{-4} \mathrm{~g} / \mathrm{ml}$ ). (C) Examples of the i.p.s evoked by single and repeated stimulations in normal and 4-AP $(\mathrm{g} / \mathrm{ml})$ solutions. $\mathrm{N}$ : control.
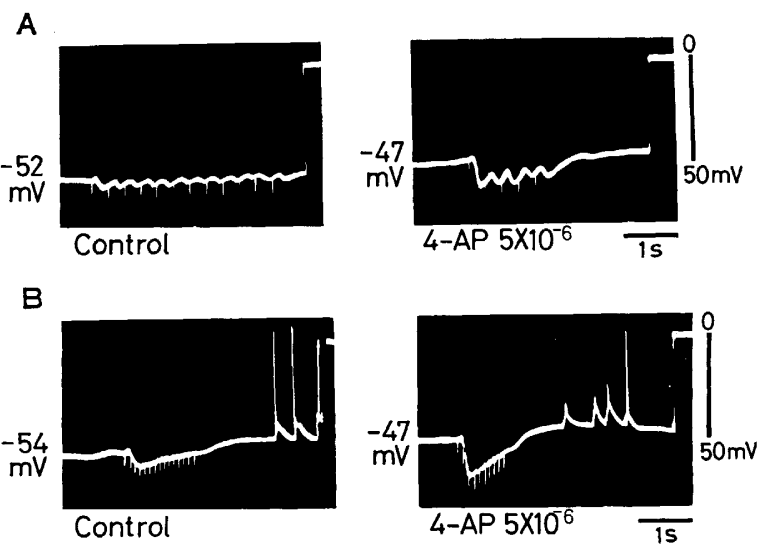

Fig. 2. Effects of 4-AP $\left(5 \times 10^{-6} \mathrm{~g} / \mathrm{ml}\right)$ on the i.p.s in the circular smooth muscles of duodenum. (A) i.p.s evoked at low and (B) high frequency of stimulations. Left side in each panel indicates the resting membrane potential level. 
of the i.p.s was increased by 4-AP $\left(2 \times 10^{-4} \mathrm{~g} / \mathrm{ml}\right)(158.2 \pm 0.5 \%$ of control, $n=58$, $p<0.001$ ).

In some preparations, the evoked i.p.s in the circular smooth muscle cells were recorded. In the circular smooth muscle cells, the amplitude of the i.p.s was enhanced and the membrane potential was decreased by $4-A P\left(5 \times 10^{-6} \mathrm{~g} / \mathrm{ml}\right)$. Examples of the potentiated i.p.s in the circular smooth muscles are shown in Fig. 2.

Effects of 4-AP on the i.p.s in various calcium concentrations

In a low-calcium solution $(0.25 \mathrm{~mm} \mathrm{Ca})$, the membrane of duodenal smooth muscle cells was depolarized from $-52.0 \pm 1.0 \mathrm{mV}(n=45)$ to $-46.6 \pm 0.9 \mathrm{mV}$ $(n=30, p<0.001)$. In this solution, the amplitude of the i.p.s elicited by single stimuli was decreased ( $73 \%$ of control, $n=26, p<0.001)$. These results confirmed the previous data (HolmAn and WeINRICH, 1975; LANG, 1979; OHKAWA, 1984). When 4-AP $\left(5 \times 10^{-4} \mathrm{~g} / \mathrm{ml}\right)$ was added in the low-calcium solution, the membrane potential was further decreased to $-43 \mathrm{mV}$ and the amplitude of the i.p.s was in-

A

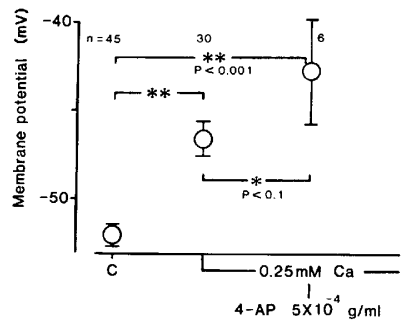

B

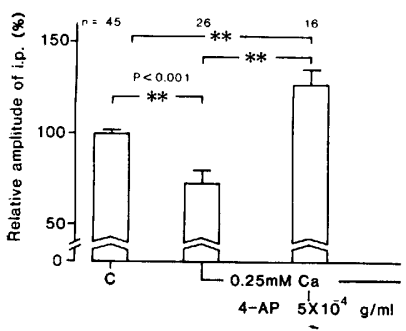

C 1

Control

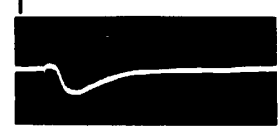

$\mathrm{Ca}_{\mathrm{Ca}}^{0.25 \mathrm{mM}}$

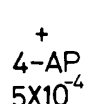

$5 \times 10^{-4}$

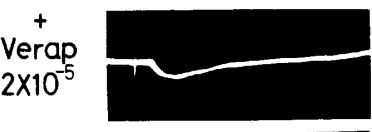

is
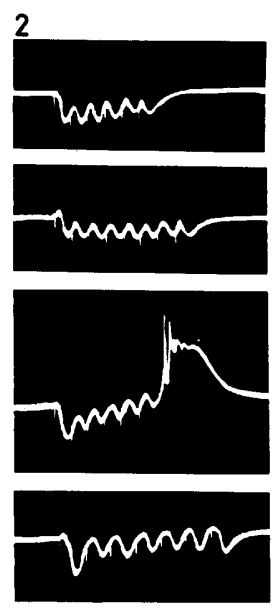

+ EGTA ImM

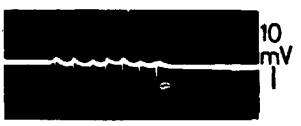

+EGTA $2 \mathrm{mM}$

Fig. 3. Effects of 4-AP on the membrane potential and the i.p.s of the longitudinal smooth muscles in the low-calcium solution. (A) Membrane potentials in normal (N), lowcalcium $(0.25 \mathrm{~mm})$, and $4-\mathrm{AP}\left(5 \times 10^{-4} \mathrm{~g} / \mathrm{ml}\right)$ solutions. (B) Changes in the relative amplitude of the i.p.s in above solutions. (C) Examples of the i.p.s evoked by single (1) and repeated (2) stimulations in above solutions. Lower panels in $\mathrm{C}$ show the effects of verapamil $\left(1 ; 2 \times 10^{-5} \mathrm{~g} / \mathrm{ml}\right)$ and $\operatorname{EGTA}(2 ; 1-2 \mathrm{mM})$ on the i.p.s. These drugs were added to the 4-AP containing low-calcium solution. 
A

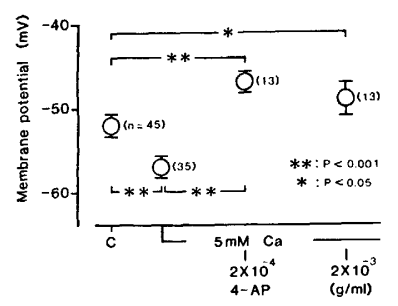

B

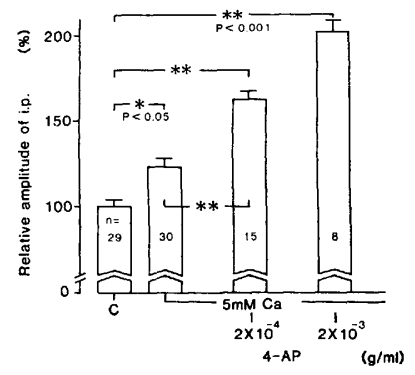

C 1
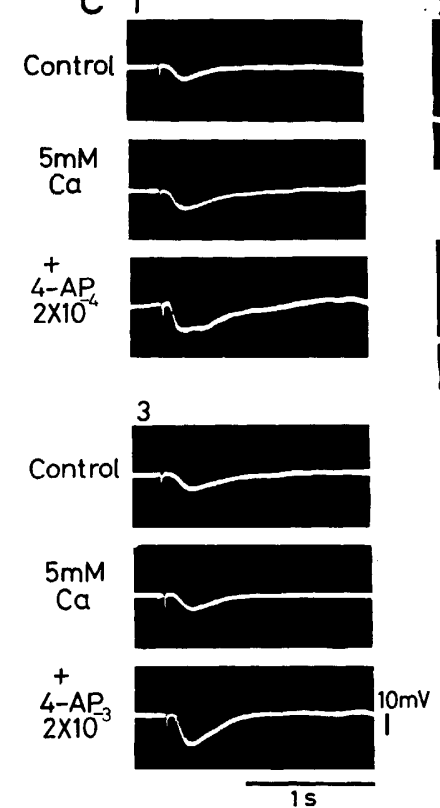

2
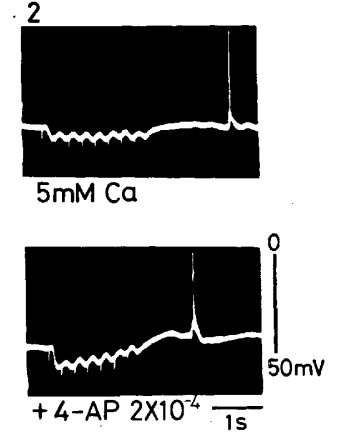

Fig. 4. Effects of 4-AP on the membrane potential and the i.p.s of the longitudinal smooth muscles in the high-calcium solution. (A) Membrane potentials in normal (N), highcalcium ( $5 \mathrm{~mm}$ ), 4-AP $2 \times 10^{-4} \mathrm{~g} / \mathrm{ml}$ and $2 \times 10^{-3} \mathrm{~g} / \mathrm{ml}$ in the high-calcium solution. (B) Changes in the relative amplitude of the i.p.s evoked in above solutions. (C) Examples of the i.p.s evoked by single (1 and 3) and repeated (2) stimulations in above solutions.

creased to $127 \%$ of control values in normal Krebs solution. These changes in the membrane potential and the relative amplitude of the i.p.s are shown in Fig. 3A and B. Examples of the i.p.s evoked by single and repeated stimulations in these solutions are shown in Fig. 3C.

The i.p.s evoked in the 4-AP containing low-calcium were inhibited by verapamil. In verapamil $\left(2 \times 10^{-5} \mathrm{~g} / \mathrm{ml}\right)$, the mean amplitude of the i.p.s was $85.7 \pm$ $0.7 \%(n=19)$ of the control values in normal solution and the membrane potential was $-44.6 \pm 1.9 \mathrm{mV}(n=17)$ (Fig. 3C-1). The amplitude of i.p.s caused by single stimuli in the low-calcium solution were markedly reduced by verapamil $(2 \times$ $10^{-5} \mathrm{~g} / \mathrm{ml}$ ). The amplitude of i.p.s elicited in the 4-AP containing low-calcium were also markedly reduced by EGTA (1-2 mM). At the concentration of $2 \mathrm{~mm}$ EGTA, the amplitude of the i.p.s during the initial 10 min of perfusion was $55.2 \pm$ $0.4 \%(n=16)$ of control values and gradually abolished (Fig. 3C-2).

In the low-calcium solution $(0.25 \mathrm{mM} \mathrm{Ca})$, the addition of barium ions $(0.4$ $\mathrm{mM} \mathrm{Ba}$ ) restored the amplitude of the i.p.s but decreased the membrane potential. The membrane potentials were $-51 \mathrm{mV}(n=18)$ in normal solution and $-47 \mathrm{mV}$ 


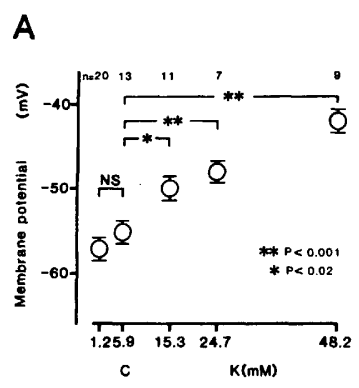

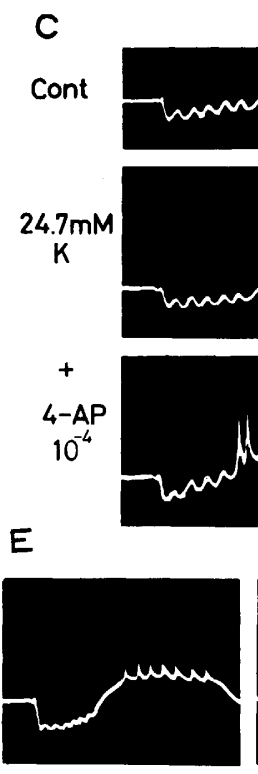

Cont

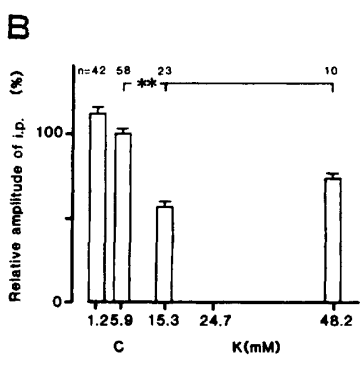

D Cont

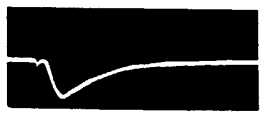

$48.2 \mathrm{mM}$

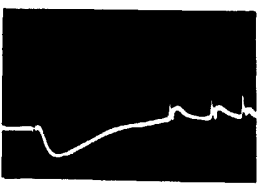

$\stackrel{+}{4-A P}$

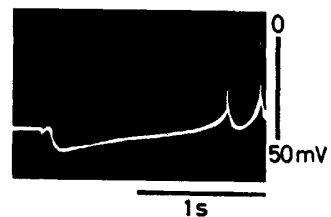

$\overline{15}$

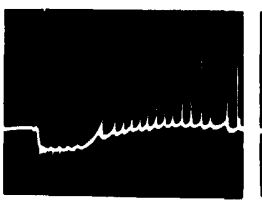

$48.2 \mathrm{mM} \mathrm{K}$

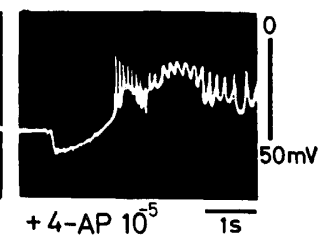

Fig. 5. Effects of 4-AP on the membrane potential and the i.p.s of the longitudinal smooth muscles in various concentrations of potassium ions. (A) Membrane potentials in various concentrations of potassium $(1.2-48.2 \mathrm{~mm})$. $\mathrm{N}$ : control. (B) Changes in the relative amplitude of the i.p.s evoked by single stimuli in various concentrations of potassium. (C-E) Examples of the i.p.s elicited by single (D) and repeated (C and E) stimulations in the 4-AP containing high-potassium solutions (C, $24.7 \mathrm{~mm}$; D and E, $48.2 \mathrm{mM})$.

$(n=16)$ in the barium containing low-calcium solution. The relative amplitudes of the i.p.s were $88 \%$ of control $(n=40)$ in the low-calcium and $105 \%$ of control $(n=23)$ in the barium containing low-calcium solution. The effect of 4-AP $\left(10^{-4}\right.$ $\mathrm{g} / \mathrm{ml}$ ) on the amplitude of i.p.s evoked in the barium containing low-calcium solution was not significant; that is, enhancement of the i.p. amplitude was absent while the membrane potential was further decreased by 4 -AP $(-40 \mathrm{mV}, n=12)$.

When the external calcium concentration increased to $5 \mathrm{mM}$, the membrane potential and the amplitude of the i.p.s were increased (Fig. 4A, B). In this solution, 4-AP $\left(2 \times 10^{-4}\right.$ and $\left.2 \times 10^{-3} \mathrm{~g} / \mathrm{ml}\right)$ further enhanced the amplitude of the i.p. but reduced the membrane potential (Fig. 4A, B). Fig. 4C shows examples of the i.p.s caused by single and repeated stimulations in these solutions.

\section{Effects of 4-AP on the i.p.s in high-potassium solutions}

The concentration of external potassium ions was varied from 1.2 to 48.2 mM. As shown in Fig. 5A, the membrane potential of the duodenal smooth muscles ranged from -57 to $-42 \mathrm{mV}$ and the change in the membrane potential 
depended on the external potassium concentrations. The i.p.s could be evoked even in high-potassium solution $(48.2 \mathrm{~mm} \mathrm{~K})$. The relative amplitude of the i.p.s caused by single stimuli was slightly enhanced by the low-potassium (1.2 mM $\mathrm{K}$ ) and decreased by the high-potassium (15.3-48.2 mM K). Figure 5A and B show the changes in the membrane potential and the amplitude of the i.p.s evoked by single stimuli.

In the low-potassium solution, the latency and the rate of hyperpolarization of the i.p. were increased significantly. These changes in the i.p. parameters were consistent with the previous report (HIDAKA and KurIYAMA, 1969). In the high-potassium solution (15.3 $\mathrm{mm} \mathrm{K}$ ), the latency and the time to peak of i.p. were prolonged and the rate of hyperpolarization of i.p. was decreased.

In the high-potassium solutions (24.7 and $48.2 \mathrm{mM} \mathrm{K}$ ), the effects of 4-AP $\left(10^{-5}\right.$ and $\left.10^{-4} \mathrm{~g} / \mathrm{ml}\right)$ on the i.p. were examined. Figure $5 \mathrm{C}-\mathrm{E}$ show the effects of 4-AP on the i.p.s evoked in the high-potassium solutions. The amplitude of the i.p. in some cells was enhanced slightly by 4-AP, but generally the effect of 4-AP on the i.p. was not significant. The off-depolarization due to the preceding i.p.s was enhanced in the high-potassium solution with and without 4-AP (Fig. 5E).

A
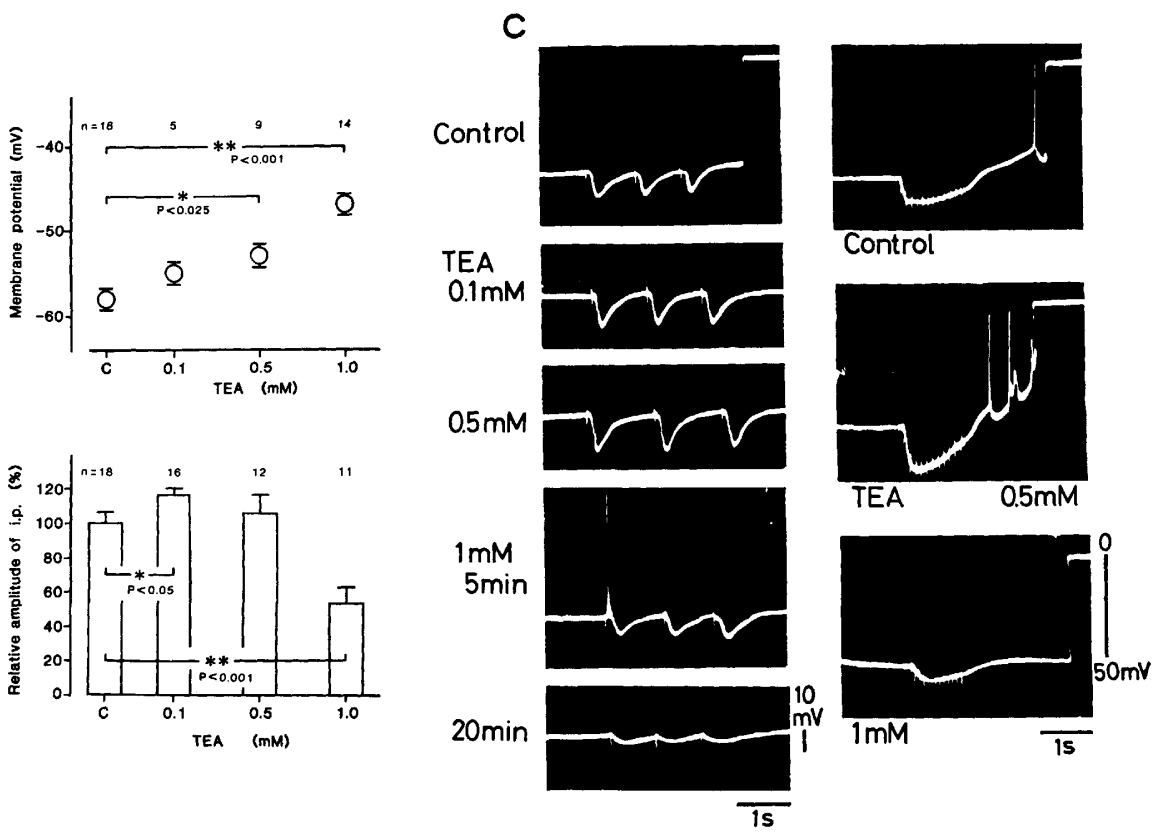

B

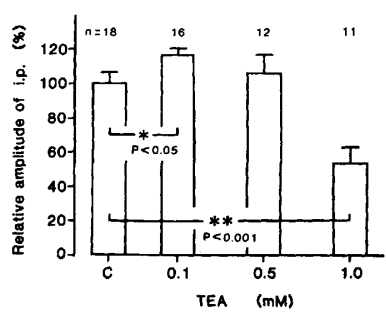

Fig. 6. Effects of TEA on the membrane potential and the i.p.s of the longitudinal smooth
muscles. (A) Membrane potentials in normal (N) and TEA solutions (0.1-1 mM). (B) Changes in the relative amplitude of the i.p.s evoked by single stimuli in various concentrations of TEA. (C) Examples of the i.p.s in TEM solutions. Times in C (lower panels) indicate the perfusion period of $1 \mathrm{mM}$ TEA. 
A
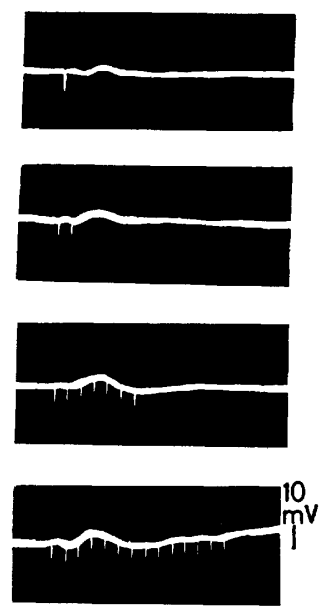

15
B
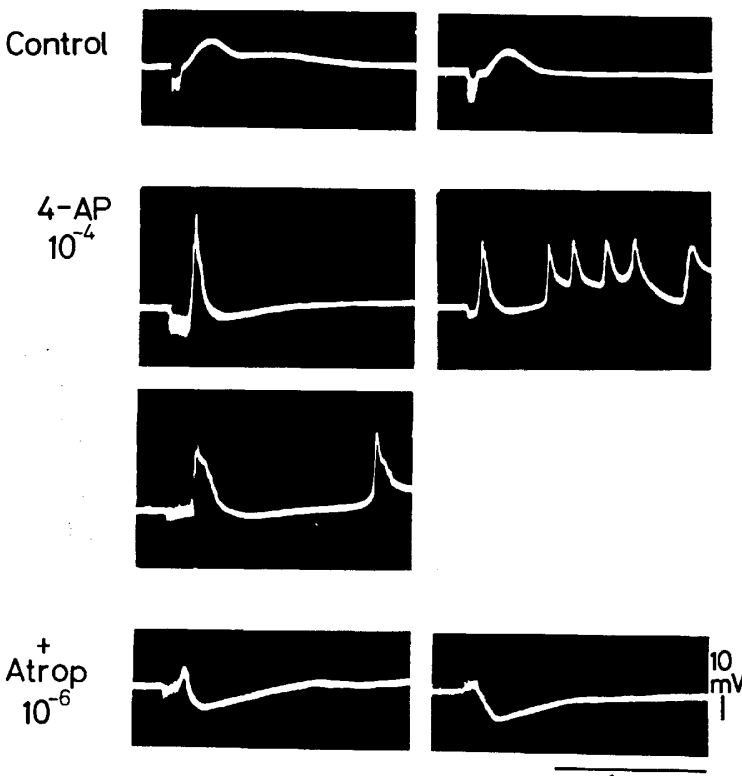

15

Fig. 7. Effects of 4-AP on the e.p.s in the longitudinal smooth muscle of duodenum. (A) e.p.s evoked by field stimulation. In this cell, the evoked i.p. was not observed in normal solution. (B) Effects of 4-AP $\left(10^{-4} \mathrm{~g} / \mathrm{ml}\right)$ on the e.p.s Middle panels show the enhancement of the e.p.s by 4-AP. Lower panels show the inhibition of the e.p.s caused by atropine $\left(10^{-6} \mathrm{~g} / \mathrm{ml}\right)$ and the evoked i.p.

\section{Effects of 2-AP and 2,5-DAP on the i.p.s}

The effects of 2-AP and 2,5-DAP on the i.p.s were examined. The membrane of the duodenal smooth muscle cells were depolarized significantly by 2-AP; the membrane potentials were $-57.3 \pm 1.2 \mathrm{mV}(n=14)$ in normal solution, and $-46.8 \pm 0.6 \mathrm{mV}(n=16, p<0.001)$ and $-44.1 \pm 0.7 \mathrm{mV}(n=16, p<0.001)$ at $10^{-5}$ and $10^{-4} \mathrm{~g} / \mathrm{ml} \mathrm{2-AP,} \mathrm{respectively,} \mathrm{while} \mathrm{it} \mathrm{was} \mathrm{unaltered} \mathrm{at} \mathrm{the} \mathrm{concentration} \mathrm{of}$ $10^{-4} \mathrm{~g} / \mathrm{ml} 2,5$-DAP. The relative amplitude of the i.p.s elicited by single stimuli was decreased by 2-AP and 2,5-DAP at concentrations above $10^{-4} \mathrm{~g} / \mathrm{ml}(77-78 \%$ of control, $n=13-23, p<0.001$ ).

\section{Effects of TEA on the i.p.s}

The membrane potential of the duodenal muscle cells was decreased by tetraethylammonium (TEA) $1 \mathrm{~mm}(-58.2 \pm 1.0 \mathrm{mV}(n=18)$ in control and -47.3 $\pm 0.8 \mathrm{mV}(n=14, p<0.001)$ in TEA). At low concentration of TEA $(0.1 \mathrm{mM})$, change in the membrane potential was not significant (Fig. 6A). In the TEA solutions, the mean amplitude of the i.p.s was changed biphasically (Fig. 6B). At the low concentration of TEA $(0.1 \mathrm{~mm})$, the amplitude of the i.p.s was increased 
$(117.1 \pm 3.6 \%$ of control, $n=16, p<0.05)$ while it was reduced at $1 \mathrm{mM}$ of TEA $(54.1 \pm 8.5 \%$ of control, $n=11, p<0.001)$. These changes on the i.p.s in TEA solution are shown in Fig. 6C. After a long perfusion $(20 \mathrm{~min})$ of TEA $1 \mathrm{~mm}$, the i.p.s were markedly inhibited.

\section{Effects of 4-AP on the e.p.s}

In the duodenal preparations, a few e.p. generating cells were observed. In a series of experiments, the percentage of the e.p. generating cells was less than $1 \%$ of the observed cells. Figure 7A shows examples of the e.p.s evoked by field stimulation. An evoked i.p. in this type of cell was not observed in normal solution. As shown in Fig. 7B, the e.p.s in normal solution were enhanced by 4-AP $\left(10^{-6} \mathrm{~g} / \mathrm{ml}\right)$. During the treatment with 4-AP, atropine $\left(10^{-6} \mathrm{~g} / \mathrm{ml}\right)$ blocked the evoked e.p.s revealing an evoked i.p. in the same cell. "Spontaneous" e.p. in the e.p. generating cell was not observed even with the 4-AP treatment.

\section{DISCUSSION}

It is well known that 4-AP potentiates cholinergic and adrenergic neuromuscular transmission (see review of THESLEFF, 1980). In the intestinal smooth muscles, the third type of innervation, non-adrenergic inhibitory neuromuscular transmission, is proposed (see review of BURNSTOCK, 1972; FURNESS and CosTA, 1980). From the effect of divalent cations on the non-adrenergic inhibitory neurotransmission, an important participation of external calcium ions on mediator release has been discussed (HolmaN and WeINRICH, 1975; OHKAWA, 1984). The effects of 4-AP on synaptic transmission are the blockade of potassium channels and the prolongation of action potential of the nerve terminals, effects which increase the duration of the opening of voltage-dependent calcium channels and the calcium influx (THesLefF, 1980). Therefore, it is interesting to examine whether or not 4-AP increases the release of inhibitory neurotransmitter which was influenced by external calcium ions.

In the present experiments, it is demonstrated that 4-AP potentiated the amplitude of evoked i.p.s of the guinea-pig duodenum. Potentiation caused by 4-AP on the i.p. was also observed in low- and high-calcium silutions. Enhancement of i.p. amplitude suggests that the impulse-evoked release of non-adrenergic inhibitory neurotransmitter is increased by 4-AP. It is unlikely that 4-AP can replace calcium ions in the coupling between nerve terminal depolarization and transmitter release, because 4-AP failed to enhance the non-adrenergic inhibitory neurotransmitter release in the presence of verapamil and EGTA. In the neuromuscular junction, a similar conclusion has been obtained from the results based on the action of magnesium ions, a blocker of membrane permeability to calcium (Molgó et al., 1977; LuNDH, 1978; Illés and ThesLefF, 1978).

The action of 4-AP in the neuromuscular junction is thought to be presynaptic 
(Molgó et al., 1977; LundH, 1978). An action of 4-AP on the smooth muscle membrane of portal vein (LEANDER et al., 1977), other vascular smooth muscles (HARA et al., 1980), and tracheal smooth muscles (KANNAN et al., 1983) has been reported. With the action of 4-AP on potassium conductance in the muscle cell membrane, especially the results are not consistent. In the present experiments, the membrane potential of the duodenal smooth muscle cells was decreased by 4-AP. If this depolarization is caused by a direct action similar to that in the vascular smooth muscles, possibly reduction in resting potassium conductance, the difference between the membrane potential and the reversal potential of the i.p., which was estimated about $-90 \mathrm{mV}$ (BYwATER et al., 1981), will be increased. Therefore, an increase in amplitude of the i.p. may occur unrelated to an increase in the amount of non-adrenergic inhibitory neurotransmitter release. However, this interpretation can be questioned because the amplitude of the i.p. was increased while the membrane was hyperpolarized in the low-potassium solution and vice versa.

The effect of high potassium on the non-adrenergic inhibitory neurotransmitter release is not clear, but KIRPEKAR and WAKADE (1968) suggested that the release of noradrenaline from the sympathetic nerve endings was increased by high potassium. In a low-calcium solution, the inhibitory action of verapamil on the i.p. was less in the presence of 4-AP than that in the absence of 4-AP. This suggests that the influx of calcium ions during depolarization of the nonadrenergic inhibitory nerve terminals is increased by 4-AP, but the problem that the low-calcium solution effects potassium conductance in the muscle membrane as well as the nerves cannot be excluded.

BAUER and KURIYAMA (1982b) have reported that the non-adrenergic i.p.s in ileal smooth muscle were decreased in amplitude by TEA $(10 \mathrm{mM})$. In the present experiments, the change in amplitude of the i.p. by TEA (0.1-1 mM) treatment was biphasic. The amplitude of the i.p. was increased by low-TEA concentrations without membrane potential change. TEA increases the release of neurotransmitter from sympathetic nerves (THOENEN et al., 1967; KIRPEKAR et al., 1977) and cholinergic nerves (LUNDH and THESLEFF, 1977) due to prolongation of action potential in nerve terminals. Enhancement in amplitude of the i.p. in the duodenal smooth muscle in low-TEA solution is thought to be due to increase in the nonadrenergic inhibitory neurotransmitter liberation. This interpretation may support the increase of calcium influx by $4-\mathrm{AP}$ in the non-adrenergic inhibitory nerve terminals.

Only in a few cells of the duodenal smooth muscles was e.p. elicited. This result indicates a minor distribution of the excitatory nerves in the guinea-pig duodenum. Since the e.p. was completely blocked by atropine treatment, it is clear that the nature of the e.p. is cholinergic. The amplitude of the e.p. was potentiated by 4-AP. In the cholinergic neuromuscular transmission, there is established evidence of an increase of acetylcholine release by 4-AP (MolGó et al.,

Vol. 34 , No. 5, 1984 
1977; Illés and TheSLefF, 1978; BURLeY and JACOBS, 1981; THOMSEN and Wilson, 1983). Therefore, it is tentatively concluded that the liberation of cholinergic neurotransmitter in the duodenal tissue is enhanced by 4-AP. It is interesting that, in the duodenal smooth muscles, "adrenergic inhibitory potential" caused by field stimulation was not observed throughout the present experiments.

The author thanks Prof. E. E. Daniel, McMaster University, for his critical reading of this manuscript as well as for valuable discussions.

\section{REFERENCES}

Bauer, V. and Kuriyama, H. (1982a) Evidence for non-cholinergic, non-adrenergic transmission in the guinea-pig ileum. J. Physiol. (Lond.), 330: 95-110.

BAUER, V. and KURIYAMA, H. (1982b) The nature of non-cholinergic, non-adrenergic transmission in longitudinal and circular muscles of the guinea-pig ileum. J. Physiol. (Lond.), 332: 375-391.

Bostock, H., Sears, T. A., and Sherratt, R. M. (1981) The effects of 4-aminopyridine and tetraethylammonium ions on normal and demyelinated mammalian nerve fibers. J. Physiol. (Lond.), 313: 301-315.

Burley, E. S. and JACOBS, R. S. (1981) Effects of 4-aminopyridine on nerve terminal action potentials. J. Pharmacol. Exp. Ther., 219: 268-273.

BuRnstock, G. (1972) Purinergic nerves. Pharmacol. Rev., 24: 509-581.

Bywater, R. A. R., Holman, M. E., and TaYlor, G. S. (1981) Atropine-resistant depolarization in the guinea-pig small intestine. J. Physiol. (Lond.), 316: 369-378.

Corthay, J., Dunant, Y., and Loctin, F. (1982) Acetylcholine changes underlying transmission of a single nerve impulse in the presence of 4-aminopyridine in Torpedo. J. Physiol. (Lond.), 325: 461-479.

Durant, N. N. and Marshall, I. G. (1980) The effects of 3,4-diaminopyridine on acetylcholine release at the frog neuromuscular junction. Eur. J. Pharmacol., 67: 201-208.

Furness, J. B. and CostA, M. (1980) Types of nerves in the enteric nervous system. Neuroscience, 5 : 1-20.

Glover, W. E. (1980) Parasympathomimetic action of an aminopyridine and sympathomimetic action of a methylaminopyridine in cardiac muscle. J. Physiol. (Lond.), 308: 42P.

Hara, Y., Kitamura, K., and Kuriyama, H. (1980) Actions of 4-aminopyridine on vascular smooth muscle tissues of the guinea-pig. Br. J. Pharmacol., 68: 99-106.

Hidaka, T. and Kuriyama, H. (1969) Responses of the smooth muscle membrane of gyinea pig jejunum elicited by field stimulation. J. Gen. Physiol., 53; 471-486.

Holman, M. E. and WeInRICH, J. P. (1975) The effects of calcium and magnesium on inhibitory junctional transmission in smooth muscle of guinea pig small intestine. Pflügers Arch., 360: 109-119.

ILlÉs, P. and TheSLEFF, S. (1978) 4-Aminopyridine and evoked transmitter release from motor nerve endings. $\quad B r . J$. Pharmacol., 64: 623-629.

Kannan, M. S., JAGer, L. P., Daniel, E. E., and Garfield, R. E. (1983) Effects of 4-aminopyridine and tetraethylammonium chloride on the electrical activity and cable properties of cannine tracheal smooth muscle. J. Pharmacol. Exp. Ther., 227: 706-715.

Kiloh, N., Harvey, A. L., and Glover, W. E. (1981) Actions of 4-methyl-2-aminopyridine on neuromuscular transmission and contractility of skeletal muscle. Eur. J. Pharmacol., 70: 53-57.

KIRPEKar, M., KIRPeKar, S. M., and Prat, J. C. (1977) Effects of 4-aminopyridine on release 
of noradrenaline from the perfused cat spleen by nerve stimulation. J. Physiol. (Lond.), 272: $517-528$.

KirpeKar, S. M. and WaKade, A. R. (1968) Release of noradrenaline from the cat spleen by potassium. J. Physiol. (Lond.), 194: 595-608.

LANG, R. J. (1979) The effects of calcium and magnesium ions, temperature and repetitive stimulation on inhibitory junctional transmission in smooth muscle of guinea-pig small intestine. Br. J. Pharmacol., 67: 39-49.

Leander, S., Arner, A., and Johansson, B. (1977) Effects of 4-aminopyridine on mechanical activity and noradrenaline release in the rat portal vein in vitro. Eur. J. Pharmacol., 46: 351-361.

Llinás, R., WAlton, K., and BoHr, V. (1976) Synaptic transmission in squid giant synapse after potassium conductance blockage with external 3- and 4-aminopyridine. Biophys. J., 16: 83-86.

LUNDH, H. (1978) Effects of 4-aminopyridine on neuromuscular transmission. Brain Res., 153: 307-318.

LUNDH, H. and TheSLEF, S. (1977) The mode of action of 4-aminopyridine and guanidine on transmitter release from motor nerve terminals. Eur. J. Pharmacol., 42: 411-412.

Molgó, J., Lemeignan, M., and Lechat, P. (1977) Effects of 4-aminopyridine at the frog neuromuscular junction. J. Pharmacol. Exp. Ther., 203: 653-663.

Molgó, J., Lemeignan, M., and Lechat, P. (1979) Analysis of the action of 4-aminopyridine during repetitive stimulation at the neuromuscular junction. Eur. J. Pharmacol., 53: 307311.

Molgó, J., Lundh, H., and TheslefF, S. (1980) Potency of 3,4-diaminopyridine and 4-aminopyridine on mammalian neuromuscular transmission and the effect of $\mathrm{pH}$ changes. Eur. J. Pharmacol., 61: 25-34.

OHKAWA, H. (1983) Inhibitory junction potentials of the guinea-pig duodenum in the treatment with catecholamines. Tohoku J. exp. Med., 140: 209-219.

OHKAWA, H. (1984) Effects of divalent cations on the inhibitory potentials in the duodenal smooth muscle cells of the guinea-pig. Jpn. J. Physiol., 34: 407-425.

THESLEFF, S. (1980) Aminopyridines and synaptic transmission. Neuroscience, 5: 1413-1419.

Thoenen, H., Haefely, W., and Staehelin, H. (1967) Potentiation by tetraethylammonium of the response of the cat spleen to postganglionic symapthetic nerve stimulation. J. Pharmacol. Exp. Ther., 157: 532-540.

Thomsen, R. H. and Wilson, D. F. (1983) Effects of 4-aminopyridine and 3,4-diaminopyridine on transmitter release at the neuromuscular junction. J. Pharmacol. Exp. Ther., 227: 260 265. 